\title{
Radial artery diameterand and age related functional maturation of the radio-cephalic arteriovenous fistula
}

\author{
Zi-ming Wan ${ }^{1 \dagger}$, Bo Hu², Qi-quan Lai ${ }^{1}$, Xue-jing Gao', Bo Tu ${ }^{3}$, Yu Zhou ${ }^{1 *}$ and Wen-bo Zhao ${ }^{4^{*}}$ (D
}

\begin{abstract}
Background: Previous studies have not described the relationship between reducing radial artery diameter as well as increasing age and functional maturation of the radio-cephalic arteriovenous fistula (RCAVF) and no data identify these as linear relationship. The objective of this study was to perform trend analysis to assess these aspects.

Methods: Our retrospective cohort study enrolled and analyzed 353 follow-up cases that underwent first AVF creation. The artery and vein sizes were measured by ultrasound. We performed follow-up, a minimum of 3 months after surgery. Multivariable logistic regression analysis was used to identify independent risk factors inmaturation. Participant age was categorized into four groups (age $\leq 29,30-49,50-69$, and 70-90 years). Radial artery diameter was categorized into four groups $(\leq 1.9,>1.9$ and $\leq 2.1,>2.1$ and $\leq 2.4,>2.4 \mathrm{~mm}$ ) according to median and interquartile ranges. We adjusted for confounders in four logistic models, and primary analyses were based on building ordered category models and tested $P$ values for trends to estimate the relationship of radial artery diameter and each 20-year increase in age with risk of maturation.
\end{abstract}

Results: The mature RCAVF group included 301 cases, and the immature group included 52 cases. Radial artery diameter, age, and diabetes were independent risk factors of maturation. Odds ratios (ORs) associated with maturation reduced with increasing age, while ORs increased with increasing radial artery diameter. $P$ values for trends $(<0.05)$ were observed in all four models. A reduction in radial artery diameter and higher age were significantly associated with a higher incidence of immaturity after adjusting the multivariate models. The risks of immaturation were increased by more than 1.54 fold for each 20-year increase and increased by more than 1.34 fold for the smaller radial artery diameter group.

Conclusion: Our findings suggest that a significantly higher immaturity risk of RCAVF was associated with increasing age and a reduction in radial artery diameter. Our study identified a linear exposure-response relationship of age and radial artery diameter with immaturity incident. A careful selection of patients will be helpful in improving AVF functional maturation.

Keywords: Radio-cephalic Arteriovenous fistula, Functional maturation, Age, Radial artery diameter

\footnotetext{
*Correspondence: 117752531@qq.com; bobo800101@foxmail.com

${ }^{\dagger}$ Zi-ming Wan and Bo Hu contributed equally to this work.

'Department of Nephrology, The First Affiliated Hospital of Chongqing Medical University, Youyi Road 1, Chongqing 400042, China

${ }^{4}$ Department of Nephrology, The Third Affiliated Hospital of Sun Yat-sen University, Tianhe Road NO.600, Guangzhou 510632, China

Full list of author information is available at the end of the article
}

\section{Background}

Vascular access is the "life-line" for hemodialysis in patients. Functional maturation of the arteriovenous fistula (AVF) is vital for hemodialysis treatment. Autogenous AVFs are the first choice for vascular access for hemodialysis in patients [1]. AVF is the best vascular

(c) The Author(s). 2020 Open Access This article is licensed under a Creative Commons Attribution 4.0 International License, which permits use, sharing, adaptation, distribution and reproduction in any medium or format, as long as you give appropriate credit to the original author(s) and the source, provide a link to the Creative Commons licence, and indicate if changes were made. The images or other third party material in this article are included in the article's Creative Commons licence, unless indicated otherwise in a credit line to the material. If material is not included in the article's Creative Commons licence and your intended use is not permitted by statutory regulation or exceeds the permitted use, you will need to obtain permission directly from the copyright holder. To view a copy of this licence, visit http://creativecommons.org/licenses/by/4.0/. The Creative Commons Public Domain Dedication waiver (http://creativecommons.org/publicdomain/zero/1.0/) applies to the data made available in this article, unless otherwise stated in a credit line to the data. 
access for hemodialysis in patients; it allows better follow-up; has better outcomes [2, 3].

Overall, 28 to $53 \%$ of AVFs have been reported to fail to develop sufficiently for dialysis [4]. AVFs are associated with high non-maturation rates [5]. Multiple factors, including age and vessel diameter, are involved in functional maturation [6]. Older people havea high risk for diabetes and peripheral vascular disease. The literature reports on influence of age on access maturation are conflicting. Some studies have reported no difference in AVF maturation with advanced age [7-9] while other studies have reached contrasting conclusions, showing that elderly individuals with radio-cephalic AVFs (RCAVFs) had lower maturation [10-14]. Therefore, the optimal vascular access in the elderly for renal replacement therapy (RRT) remains controversial [15].

A diameter of the radial artery in the range of 1.5 to > $2 \mathrm{~mm}$ with regard to maturation and primary patency is highly advocated [16]; however, the relationship between artery diameter change and maturation rate is unclear.

There are no data to identify whether there is a linear relationship of increasing age and reducing radial artery diameter with functional maturation The objective of the present study was to perform a trend analysis of increasing age and reducing radial artery diameter with primary functional maturation using a retrospective cohort, which can be helpful in medical decision-making for dialysis patients.

\section{Methods}

\section{Selection of patients}

Our study population was derived from a retrospective cohort with end-stage renal disease (ESRD) and who underwent hemodialysis from 10/1/2018 to 8/30/ 2019 at the Department of Nephrology, the primary affiliated hospital of Chongqing medical university. The patients were followed monthly at the outpatient clinic or in-person by telephone as per patient's preference or convenience. A total of 435 adult patients were planned to receive RCAVF creation under local anesthesia in this study. Our study excluded patients who had undergone middle-forearm radio-cephalic AVF creation and patients less than 18 years of age $(n=42)$. We confirmed that 393 patients had received first RCAVF creation by end-to-side anastomosis. We followed patients after surgery until death, loss to follow-up, or failure to maturewith a minimum follow-up of 4 months. We excluded patients who died before maturity and those who were lost to follow-up $(n=40)$. Ultimately, our study enrolled and analyzed 353 follow-up cases. The selection of study participants is described in Fig. 1. Patients' demographics included age, sex, body mass index, and smoking history. Diabetes was included in the comorbidities analysis. Longitudinal measures of laboratory parameters (e.g. hemoglobin, serum calcium, serum phosphorus, albumin, coagulation factors, and blood lipids) were collected, and functional maturation was assessed. Ultrasound examination was performed before surgery. All ultrasound examinations were carried out by the same sonographer. Multiple sites evaluation of fistulae was carried out from the brachial artery to distal radial artery, and from distal cephalic vein to upper arm cephalic vein. After bundling arm for more than $1 \mathrm{~min}$, cephalic vein diameters were measured. Two different cross-sectional vascular diameters of cephalic vein and radial artery at surgical sites were measured at the vessel wall interface and an average of the two diameters was recorded.

All vascular access types were created by two experienced nephrologists. AVF was created under local anesthesia by direct anastomosis between the end of the vein and the side of the artery. The threshold diameter of abandoning an RCAVF creation was as follows: radial artery $<1.5 \mathrm{~mm}$ or cephalic vein $<2.0 \mathrm{~mm}$.

\section{Definition of functional maturation}

The functional maturation of RCAVFs was an outcome of the study. Functional maturation was defined as successful 2-needle annulations during hemodialysis treatment at 4-6 weeks after surgery and a blood flow rate over $200 \mathrm{ml} / \mathrm{min}$ for at least six consecutive hemodialysis sessions. An immature fistula was defined as one that was difficult to cannulate, one that was never mature enough to be used, and/or failure to generate a sufficient blood flow rate [17].

\section{Data analysis and statistics}

The study cohort was categorized into four groups based on age: $\leq 29,30-49,50-69$, and $70-90$ years according to 20 -year increments. Radial artery diameter was categorized into four groups $(\leq 1.9,>1.9$ and $\leq 2.1,>2.1$ and $\leq$ 2.4 , and $>2.4 \mathrm{~mm}$ ) according to the median and interquartile ranges. We adjusted for several confounders in our logistic models. Model1 was adjusted for age or radial artery diameter. In model 2, we further adjusted for various covariates, including sex, smoking status, body mass index (BMI), and diabetes. In model 3 , based on model 2, we further adjusted for cephalic vein diameter and surgical sites (left side or right side). In model 4, we further adjusted for laboratory measures (e.g. hemoglobin, serum calcium, serum phosphorus, albumin, coagulation factors, and blood lipids). Primary analyses were based on tests for trends according to the age or radial artery diameter categories.

All data were analyzed using SPSS 25.0 software (IBM Corp., Armonk, NY, USA). In the baseline characteristics table, all the continuous variables with non-normal 
435 patients arranged to receive first RCAVF creation by end to side from October 2018 to August 2019

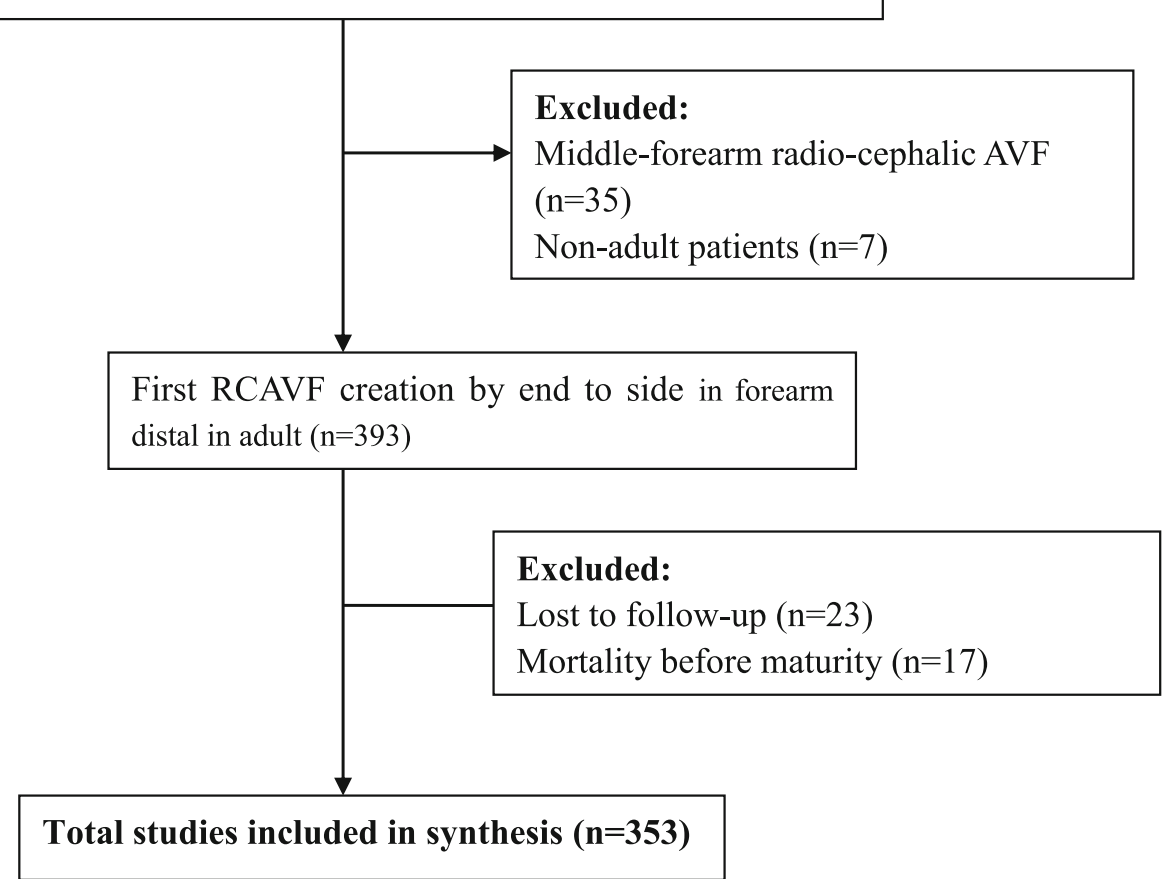

Fig. 1 Flow chart of study participants

distribution are expressed as medians and interquartile ranges (IQR) and were tested by the KolmogorovSmirnov test. Categorical variables are shown as the percentage of patients per group. All the categorical variables were analyzed with the Chi-squared test. The univariate and multivariable logistic regression models were used to identify risk factors of functional maturation. Logistic regression estimated the odds ratios (ORs) and 95\% confidence intervals (CIs). $\boldsymbol{P}$ values for trends were used to estimate the trend of relationship of each 20-year increase in age and radial artery diameter with maturity risk. A $\boldsymbol{P}$ value $<0.05$ was defined as statistically significant.

\section{Results}

\section{Characteristics of participants}

The baseline characteristics of the 353 follow-up RCAVF cases and clinical data of the study participants are summarized in Table 1. The mature RCAVF group included 301 cases, and the immature RCAVF group included 52 cases. The participants in the immature RCAVF group were significantly older and their wrist radial artery diameter was significantly smaller than those in the mature RCAVF group. Number of patients with diabetes was higher in the mature RCAVF group. However, between-group differences in sex, smoking history, BMI, surgical sites (left side or right side), cephalic vein diameter, and laboratory measures (e.g. hemoglobin, serum calcium, serum phosphorus, albumin, coagulation factors, and blood lipids) were not significant. (Table 1).

Multivariate logistic regression analysis and trend analysis of maturation outcome in multiple models

Results of the multivariate logistic regression analysis for risk factors of maturation are shown in Table 2. Age, radial artery diameter, and diabetes were independent predictors for maturation. Increasing age and reducing radial artery diameter as continuous variables suggested elevated immaturity risk. In order to compare increasing age and reducing radial artery diameter in relation to reducing primary functional maturation, we used a trend analysis of maturation for different age $(\leq 29,30-49$, $50-69$, and $70-90$ years) and radial artery diameter( $\leq$ $1.9,>1.9$ and $\leq 2.1,>2.1$ and $\leq 2.4$, and $>2.4 \mathrm{~mm}$ ) categories as components in multiple models. The ORs associated with maturation reduced with increasing age and increased with increasing radial artery diameter. $\boldsymbol{P}$ values for trends $(<\mathbf{0 . 0 5})$ were all observed in all four models (Table 3, Table 4). In the age-adjusted models, higher age was significantly associated with an increased risk of immaturity $(P<0.05)$. In the radial artery diameter adjusted models, increasing radial artery diameter was 
Table 1 Summary of the baseline characteristics of wrist RCAVFs

\begin{tabular}{|c|c|c|c|c|c|}
\hline \multirow{2}{*}{\multicolumn{2}{|c|}{ Variable }} & \multirow{2}{*}{$\begin{array}{l}\text { mature Wrist RCAVF group } \\
(n=301)\end{array}$} & \multirow{2}{*}{$\begin{array}{l}\text { Immature Wrist RCAVF group } \\
(n=52)\end{array}$} & \multirow[t]{2}{*}{$\mathrm{z} / \mathrm{x}^{2}$} & \multirow[t]{2}{*}{$P$} \\
\hline & & & & & \\
\hline \multirow[t]{2}{*}{ Gender } & male(\%) & $122(40.50)$ & $22(43.20)$ & 5.326 & 0.021 \\
\hline & female(\%) & $179(59.5)$ & $30(57.70)$ & & \\
\hline \multicolumn{2}{|c|}{ Age (years), Median (IQR) } & $57.00(46.00,67.00)$ & $61.50(52.00,74.00)$ & -2.611 & 0.009 \\
\hline \multicolumn{2}{|c|}{ Diabetes (\%) } & $111(36.90)$ & $27(51.90)$ & 4.216 & 0.040 \\
\hline \multicolumn{2}{|c|}{ Smoking history (\%) } & $129(42.90)$ & $19(36.50)$ & 0.727 & 0.394 \\
\hline \multicolumn{2}{|c|}{$\mathrm{BMI} /\left(\mathrm{kg} / \mathrm{m}^{2}\right)$, Median (IQR) } & $22.99(20.76,25.66)$ & $21.87(19.92,24.20)$ & -1.734 & 0.083 \\
\hline \multicolumn{2}{|c|}{ Left side (\%) } & $253(84.10)$ & $41(78.80)$ & 0.864 & 0.353 \\
\hline \multicolumn{2}{|c|}{ Wrist radial artery diameter $(\mathrm{mm})$, Median (IQR) } & $2.10(1.90,2.50)$ & $2.00(1.80,2.20)$ & -2.812 & 0.005 \\
\hline \multicolumn{2}{|c|}{ Wrist cephalic vein diameter (mm),Median (IQR) } & $2.50(2.20,2.80)$ & $2.30(2.10,2.70)$ & -1.694 & 0.090 \\
\hline \multicolumn{2}{|c|}{ HGB/(g/L), Median (IQR) } & $86.00(75.00,98.00)$ & $83.50(74.00,103.75)$ & -0.222 & 0.824 \\
\hline \multicolumn{2}{|c|}{ Albumin/ (g/L), Median (IQR) } & $36.00(32.00,39.00)$ & $35.00(32.00,37.38)$ & -0.599 & 0.549 \\
\hline \multicolumn{2}{|c|}{$\mathrm{Ca} /(\mathrm{mmol} / \mathrm{L})$, Median $(\mathrm{IQR})$} & $2.04(1.89,2.18)$ & $2.07(1.92,2.21)$ & -1.081 & 0.280 \\
\hline \multicolumn{2}{|c|}{$\mathrm{P} /(\mathrm{mmol} / \mathrm{L})$, Median $(\mathrm{IQR})$} & $1.78(1.46,2.20)$ & $1.73(1.29,2.45)$ & -1.651 & 0.099 \\
\hline \multicolumn{2}{|c|}{ PTH/(pg/ml), Median (IQR) } & $286.30(211.20,387.40)$ & $270.98(192.10,406.80)$ & -0.541 & 0.589 \\
\hline \multicolumn{2}{|c|}{$\mathrm{TC} /(\mathrm{mmol} / \mathrm{L})$, Median (IQR) } & $3.89(3.37,4.35)$ & $3.93(3.25,4.92)$ & -0.265 & 0.791 \\
\hline \multicolumn{2}{|c|}{$\mathrm{TG} /(\mathrm{mmol} / \mathrm{L})$, Median (IQR) } & $1.37(1.06,1.80)$ & $1.48(1.05,2.48)$ & -1.343 & 0.179 \\
\hline \multicolumn{2}{|c|}{ LDL-C/(mmol/L), Median (IQR) } & $2.25(1.80,2.63)$ & $1.96(1.66,3.06)$ & -0.951 & 0.341 \\
\hline \multicolumn{2}{|c|}{$\mathrm{HDL}-\mathrm{C} /(\mathrm{mmol} / \mathrm{L})$, Median (IQR) } & $1.09(0.88,1.28)$ & $1.10(0.85,1.30)$ & -0.096 & 0.923 \\
\hline \multicolumn{2}{|c|}{ FBG/ (s), Median (IQR) } & $4.30(3.67,5.19)$ & $4.04(3.12,4.84)$ & -1.887 & 0.059 \\
\hline
\end{tabular}

BMI Body mass index; HGB Hemoglobin; Ca Serum calcium; P Serum phosphorus; PTH parathyroidhormone; TC Total Cholesterol; TG Triglyceride; HDL-C Highdensity Lipoprotein; LDL-C Low Density Lipoprotein; PT Prothrombin time; APTT Activated partial thromboplastin time; INR International normalized ratio; FBG Fibrinogen

significantly associated with a reduced risk of immaturity $(P<0.05)$. After multivariate adjustment, we observed similar results.

\section{Multiple logistic regression models to analyze immaturity risk}

Age was used as a categorical variable, and every 20-year increase in age was significantly associated with a higher OR $(\mathrm{OR}>1.543)$ for the incidence of immaturity after multivariate adjustment (Table 5). A smaller diameter of the artery was significantly associated with a higher OR (OR > 1.349) for immaturity, after multivariate adjustment, when the radial artery diameter was considered as a categorical variable (Table 6).

\section{Discussion}

In this prospective cohort study, we found a significantly higher risk of immaturity of RCAVF associated with increasing age and reducing diameter of the radial artery. Our study identified an almost linear exposure-response relationship of age and radial artery diameter with incident immaturity. Older patients showed a greater prevalence and risk of immaturity. Each 20-year increase in age was significantly associated with an increase of more than $54 \%$ in immaturity risk after multivariate adjustment. A smaller artery diameter was related to a higher immaturity rate. Compared with the highest quartile of artery diameter, participants in the lower quartile had an increased risk of incident immaturity (by more than $34 \%)$.

Table 2 The multivariate regression analysis for maturation outcomes of RCAVFs

\begin{tabular}{|c|c|c|c|c|c|c|c|c|}
\hline \multirow[t]{2}{*}{ Variable } & \multirow[t]{2}{*}{ B } & \multirow[t]{2}{*}{ SE } & \multirow[t]{2}{*}{ Wald } & \multirow[t]{2}{*}{ df } & \multirow[t]{2}{*}{ Sig. } & \multirow[t]{2}{*}{$\operatorname{Exp}(B)$} & \multicolumn{2}{|c|}{ 95.0\% Cl for $\operatorname{Exp}(\mathrm{B})$} \\
\hline & & & & & & & Lower & Upper \\
\hline Age & -0.029 & 0.013 & 4.994 & 1 & 0.025 & 0.971 & 0.946 & 0.996 \\
\hline Diabetes & -0.939 & 0.391 & 5.753 & 1 & 0.016 & 0.391 & 0.182 & 0.842 \\
\hline Wrist radial artery diameter & 1.045 & 0.458 & 5.201 & 1 & 0.023 & 2.843 & 1.158 & 6.980 \\
\hline
\end{tabular}


Table 3 Trend analysis of maturation outcomes for different age levels components in multiple models

\begin{tabular}{|c|c|c|c|c|c|}
\hline Variable & $20-29$ & $30-49$ & $50-69$ & $70-90$ & $\begin{array}{l}\boldsymbol{P} \text { to } \\
\text { trend }\end{array}$ \\
\hline \multicolumn{6}{|l|}{ Age } \\
\hline Median (y) & 24.50 & 44.00 & 60.00 & 74.50 & \\
\hline Cases/person & $1 / 24$ & 10/83 & $22 / 164$ & $19 / 82$ & \\
\hline Model 1, OR(95\%CL) & 1.00(Ref) & $0.317(0.039,2.614)$ & $0.281(0.036,2.184)$ & $0.144(0.018,1.139)$ & 0.014 \\
\hline $\boldsymbol{P}$ Value & & 0.286 & 0.225 & 0.066 & \\
\hline Model 2, OR(95\%CL) & 1.00(Ref) & $0.341(0.040,2.894)$ & $0.369(0.045,2.989)$ & $0.175(0.021,1.443)$ & 0.041 \\
\hline $\boldsymbol{P}$ Value & & 0.324 & 0.350 & 0.105 & \\
\hline Model 3, OR(95\%CL) & 1.00(Ref) & $0.276(0.031,2.431)$ & $0.316(0.038,2.656)$ & $0.135(0.016,1.172)$ & 0.029 \\
\hline $\boldsymbol{P}$ Value & & 0.246 & 0.289 & 0.069 & \\
\hline Model 4, OR(95\%CL) & 1.00(Ref) & $0.236(0.026,2.171)$ & $0.313(0.036,2.723)$ & $0.126(0.014,1.133)$ & 0.039 \\
\hline $\boldsymbol{P}$ Value & & 0.202 & 0.293 & 0.065 & \\
\hline
\end{tabular}

OR Odds rations; 95\% CL 95\% Confidence interval; Model 1: unadjusted relevant factors; Model 2: Univariate model plus gender, $B M I$ Smoking history, diabetes; Model 3: Model 2 plus wrist radial artery diameter, wrist cephalic vein diameter, left side or right side; Model 4: Model 3 plus HGB, albumin, Ca, P, PTH, TC, TG, LDL-C, HDL-C, FBG

As populations are rapidly ageing worldwide, associated health issues have increased. The age of individuals requiring dialysisis is increasing. The elderly population requiring RRT is growing worldwide, comprising no less than 25 to $30 \%$ in most ESRD registration systems [18, 19]. In Catalan, more than half of the patients planned to start dialysis are over 60 years of age [20]. In the United States, from 1996 until 2003, the dialysis initiation rate among patients aged $>65$ years has increased by nearly $10 \%$ annually, with an overall increase of $57 \%$ [21]. In Canada, the proportion of patients aged 75 and older starting dialysis has increased by $74 \%$ between 1990 and 2001 [21].
Autogenous AVFs are recommended as the first choice for hemodialysis vascular access [22]. Previous studies reported that elderly patients with RCAVFs had lower maturation [10-14]. A meta-analysis showed that elderly patients had a 50\% increased RCAVF failure risk when compared with non-elderly patients [10]. Older patients with higher intima-media width and arterial rigidity showed increased vessel narrowing and loss of vascular elasticity [23]. The prevalence of diabetes and peripheral vascular disease increases in older individuals, and when compared with subjects without chronic kidney diseases, dialysis patients had a higher incidence of diabetes and peripheral vascular disease [24] that was in

Table 4 Trend analysis of immaturation outcomes for different radial artery diameter components in multiple models

\begin{tabular}{|c|c|c|c|c|c|}
\hline \multirow[t]{2}{*}{ Variable } & \multicolumn{4}{|c|}{ Radial artery diameter (mm) } & \multirow{2}{*}{$\begin{array}{l}\boldsymbol{P} \text { to } \\
\text { trend }\end{array}$} \\
\hline & $\leq 1.9$ & $>1.9$ and $\leq 2.1$ & $>2.1$ and $\leq 2.4$ & $>2.4$ & \\
\hline \multicolumn{6}{|l|}{ Diameter } \\
\hline Median (y) & 1.80 & 2.10 & 2.30 & 2.70 & \\
\hline Cases/person & $22 / 107$ & $14 / 83$ & $9 / 76$ & $7 / 87$ & \\
\hline Model 1, OR(95\%CL) & 1.00(Ref) & $0.338(0.137,0.835)$ & $0.431(0.165,1.129)$ & $0.651(0.230,1.842)$ & 0.011 \\
\hline$P$ Value & & 0.059 & 0.087 & 0.419 & \\
\hline Model 2, OR(95\%CL) & 1.00(Ref) & $1.251(0.573,2.732)$ & $1.831(0.768,4.363)$ & $2.841(1.085,7.441)$ & 0.023 \\
\hline$P$ Value & & 0.575 & 0.172 & 0.034 & \\
\hline Model 3, OR(95\%CL) & 1.00(Ref) & $1.231(0.563,2.692)$ & $1.820(0.763,4.339$ & $2.765(1.048,7.295)$ & 0.027 \\
\hline$P$ Value & & 0.603 & 0.177 & 0.040 & \\
\hline Model 4, OR(95\%CL) & 1.00(Ref) & $1.181(0.531,2.625)$ & $1.592(0.659,3.848)$ & $2.638(0.977,7.127)$ & 0.045 \\
\hline$P$ Value & & 0.683 & 0.302 & 0.056 & \\
\hline
\end{tabular}

OR Odds rations; 95\% CL 95\% Confidence interval; Model 1: unadjusted relevant factors; Model 2: Univariate model plus age, gender, BMI, smoking history, diabetes; Model 3: Model 2 plus wrist cephalic vein diameter, left side or right side;

Model 4: Model 3 plus HGB, albumin, Ca, P, PTH, TC, TG, LDL-C, HDL-C, FBG 
Table 5 Multiple models of logistic regression to analyze immaturity risk for different age levels

\begin{tabular}{lllllllllll}
\hline Variable & B & SE & Wald & df & Sig. & $\operatorname{Exp}(\mathrm{B})$ & \multicolumn{2}{c}{$95.0 \%$ Cl for $\operatorname{Exp}(\mathrm{B})$} \\
\cline { 7 - 10 } & & & & & & & \multicolumn{2}{c}{ Lower } & Upper \\
\hline Age & & & & & & & & \\
Model 1 & 0.482 & 0.194 & 6.188 & 1 & 0.013 & 1.620 & 1.108 & 2.368 \\
Model 2 & 0.434 & 0.208 & 4.343 & 1 & 0.037 & 1.543 & 1.026 & 2.320 \\
Model 3 & 0.478 & 0.214 & 4.980 & 1 & 0.026 & 1.614 & 1.060 & 2.456 \\
Model 4 & 0.460 & 0.218 & 4.446 & 1 & 0.035 & 1.584 & 1.033 & 2.430 \\
\hline
\end{tabular}

Model 1: Unadjusted relevant factors; Model 2: Univariate model plus gender, BMI, smoking history, diabetes; Model 3: Model 2 plus wrist radial artery diameter, wrist cephalic vein diameter, left side or right side; Model 4: Model 3 plus HGB, albumin, Ca, P, PTH, TC, TG, LDL-C, HDL-C, FBG

turn associated with increasing immaturity. Previous several comparative studies [25-27] supported preoperative ultrasound scanning. European Best Practice Guidelines suggest its routine use (level II evidence) [21]. Several meta-analysis [28-30] including only one of the few randomized clinical trials (RCTs) appeared contradicting results. Georgiadis et al. study [29] found preoperative ultrasound mapping to avoid unnecessary surgical explorations and significantly reduces the immediate AVF failure rate. We considered that the preoperative clinical examination and routine ultrasound mapping should always be performed before AVF creation. If the patient has obvious intra-arterial lesions, such as significant intimal hyperplasia, severe calcification, and vascular malformations, which cannot meet the requirements of the surgical diameter, we will not perform the surgery.

The optimal vascular access for RRT in the elderly is controversial [15]. Elbow brachiocephalic fistulas and arteriovenous grafts (AVGs) may be important alternatives in elderly patients [10]. Our study highlights a positive correlation between increasing age and the incidence of immaturity. Therefore, a careful evaluation of clinical characteristics and a clinical scoring system to establish what is essential for the increasingly ageing dialysis

Table 6 Multiple models of logistic regression to analyze immaturity risk for different radial artery diameter levels

\begin{tabular}{|c|c|c|c|c|c|c|c|c|}
\hline \multirow[t]{2}{*}{ Variable } & \multirow[t]{2}{*}{$\mathrm{B}$} & \multirow[t]{2}{*}{ SE } & \multirow[t]{2}{*}{ Wald } & \multirow[t]{2}{*}{ df } & \multirow[t]{2}{*}{ Sig. } & \multirow[t]{2}{*}{$\operatorname{Exp}(B)$} & \multicolumn{2}{|c|}{$95.0 \% \mathrm{Cl}$ for $\operatorname{Exp}(\mathrm{B})$} \\
\hline & & & & & & & Lower & Upper \\
\hline \multicolumn{9}{|c|}{ Wrist radial artery diameter } \\
\hline Model 1 & 0.354 & 0.138 & 6.569 & 1 & 0.010 & 1.425 & 1.087 & 1.868 \\
\hline Model 2 & 0.337 & 0.147 & 5.284 & 1 & 0.022 & 1.401 & 1.051 & 1.869 \\
\hline Model 3 & 0.330 & 0.148 & 5.000 & 1 & 0.025 & 1.391 & 1.042 & 1.858 \\
\hline Model 4 & 0.299 & 0.150 & 3.997 & 1 & 0.046 & 1.349 & 1.006 & 1.808 \\
\hline
\end{tabular}

Model 1: Unadjusted relevant factors; Model 2: Univariate model plus age, gender, BMI, smoking history, diabetes; Model 3: Model 2 plus wrist cephalic vein diameter, left side or right side; Model 4: Model 3 plus HGB, albumin, $\mathrm{Ca}$, P, PTH, TC, TG, LDL-C, HDL-C, FBG patient population are imperative for accurate medical decision-making.

In practice, the diameters of the radial artery and cephalic vein are evaluated by preoperative duplex ultrasound. In our study, all ultrasound examinations were carried out by the same sonographer. Niek et al. study [31] indicated that the arterial and venous diameter measurements showed excellent intra- and interobserver agreement and duplex ultrasonography was a reliable imaging modality to support AVF surgery planning. There are no definite criteria for determining a suitable artery for AVF. Radial artery diameter within a range of 1.5 to $>2 \mathrm{~mm}$ is usually selected. However, there are no data concerning the relationship of radial artery diameter with functional maturation. Our study shows that there is a linear relationship between radial artery diameter and incident immaturity. This may be beneficial in operational risk assessments and medical decision-making.

\section{Conclusions}

Our findings suggest that the risks of immaturity of RCAVF were linearly associated with increasing age and reducing radial artery diameter. Each 20-year increase in age (risk increased by more than 54\%) and a smaller radial artery diameter (risk increased by more than34\%) were associated with a higher incidence of immaturity. A careful selection of patients in different age groups who are suitable for AVFs may be helpful to improve functional maturation. Some limitations of our study must be acknowledged. Firstly, this study had a low number of patients in some groups and further studies should be performed with larger sample sizes. Secondly, many potential factors should be considered that were not evaluated in our study (e.g. peripheral vascular disease).

\section{Supplementary information}

Supplementary information accompanies this paper at https://doi.org/10. 1186/s12882-020-01883-W.

\section{Additional file 1.}

Additional file 2

\section{Abbreviations}

RCAVF: Radio-cephalic arteriovenous fistula: AVF: Arteriovenous fistula** ORs: Odds ratios; RRT: Renal replacement therapy; ESRD: End-stage renal disease; IQR: Interquartile ranges; BMI: Body mass index; AVGs: Arteriovenous grafts

\section{Acknowledgements}

Not applicable.

\section{Availability of data and material}

The datasets used and analyzed during the current study are available from the corresponding author on reasonable request. 


\section{Authors' contributions}

ZMW, WBZ and HB designed the study; WBZ, ZMW and YZ drafted the manuscript; QQL and XJG were responsible for data collection and analysis. BT was responsible for ultrasound data collection. All authors reviewed the manuscript and approved the final version of the manuscript to be published.

\section{Funding}

No funding exits regarding this manuscript.

\section{Ethics approval and consent to participate}

This study was approved by the first affiliated hospital of Chongqing medical university. Because of the retrospective design of this study, the exemption for the informed consent for each participant was granted by the Ethical Review of the first affiliated hospital of Chongqing Medical Ethics Committee. This study was carried out in accordance with the principles of the Declaration of Helsinki.

\section{Consent for publication}

Not applicable.

\section{Competing interests}

The authors declare that they have no competing interests.

\section{Author details}

'Department of Nephrology, The First Affiliated Hospital of Chongqing Medical University, Youyi Road 1, Chongqing 400042, China. ${ }^{2}$ Department of Nephrology, The First Affiliated Hospital of Jinan University, Guangzhou, China. ${ }^{3}$ Department of Ultrasonography, The First Affiliated Hospital of Chongqing Medical University, Chongqing, China. ${ }^{4}$ Department of Nephrology, The Third Affiliated Hospital of Sun Yat-sen University, Tianhe Road NO.600, Guangzhou 510632, China

Received: 26 February 2020 Accepted: 4 June 2020

Published online: 22 June 2020

\section{References}

1. NKF-DOQI clinical practice guidelines for vascular access. National Kidney Foundation-Dialysis outcomes quality initiative. Am J Kidney Dis 1997;30: S150-S191.

2. Allon M. Current management of vascular access. Clin J Am Soc Nephrol. 2007;2:786-800.

3. Polkinghorne KR, McDonald SP, Atkins RC, et al. Vascular access and all-cause mortality: a propensity score analysis. J Am Soc Nephrol. 2004;15:477-86.

4. Asif A, Cherla G, Merrill D, et al. Conversion of tunneled hemodialysis catheter-consigned patients to arteriovenous fistula. Kidney Int. 2005;67: 2399-406.

5. Al-Jaishi AA, Oliver MJ, Thomas SM, et al. Patency rates of the arteriovenous fistula for hemodialysis: a systematic review and meta-analysis. Am J Kidney Dis. 2014;63:464-78.

6. Siddiqui MA, Ashraff S, Carline T. Maturation of arteriovenous fistula: analysis of key factors. Kidney Res Clin Pract. 2017;36:318-28.

7. Swindlehurst N, Swindlehurst A, Lumgair H, Rebollo Mesa I, Mamode N, Cacciola R, et al. Vascular access for hemodialysis in the elderly. J Vasc Surg. 2011;53:1039-43.

8. Lok CE, Oliver MJ, Su J, Bhola C, Hannigan N, Jassal SV. Arteriovenous fistula outcomes in the era of the elderly dialysis population. Kidney Int. 2005;67: 2462-9.

9. Beaulieu MC, Dumaine CS, Romann A, Kiaii M. Advanced age is not a barrier to creating a functional arteriovenous fistula: a retrospective study. J Vasc Access. 2017;18:307-12.

10. Lazarides MK, Georgiadis GS, Antoniou GA, Staramos DN. A meta-analysis of dialysis access outcome in elderly patients. J Vasc Surg. 2007;45:420-6.

11. Greenberg J, Jayarajan S, Reddy S, Schmieder FA, Roberts AB, van Bemmelen PS, et al. Long-term outcomes of fistula first initiative in an Urban University hospital-is it still relevant. Vasc Endovasc Surg. 2017;51: 125-30.

12. Lee T, Qian J, Thamer M, Allon M. Tradeoffs in vascular access selection in elderly patients initiating hemodialysis with a catheter. Am J Kidney Dis. 2018;72:509-18.
13. Misskey J, Faulds J, Sidhu R, Baxter K, Gagnon J, Hsiang Y. An age-based comparison of fistula location, patency, and maturation for elderly renal failure patients. J Vasc Surg. 2018;67:1491-500.

14. Monroy-Cuadros M, Yilmaz S, Salazar-Bañuelos A, Doig C. Risk factors associated with patency loss of hemodialysis vascular access within 6 months. Clin J Am Soc Nephrol. 2010;5:1787-92.

15. Lok CE, Allon M, Moist L, Oliver MJ, Shah H, Zimmerman D. Risk equation determining unsuccessful cannulation events and failure to maturation in arteriovenous fistulas (REDUCE FTM I). J Am Soc Nephrol. 2006;17:3204-12.

16. Kordzadeh A, Chung J, Panayiotopoulos YP. Cephalic vein and radial artery diameter in formation of radiocephalic arteriovenous fistula: a systematic review. J Vasc Access. 2015;16:506-11

17. Nassar GM. Endovascular management of the "failing to mature" arteriovenous fistula. Tech Vasc Interv Radiol. 2008;11:175-80.

18. Muntner P, Coresh J, Powe NR, Klag MJ. The contribution of increased diabetes prevalence and improved myocardial infarction and stroke survival to the increase in treated end-stage renal disease. J Am Soc Nephrol. 2003; 14:1568-77.

19. Port FK. The end-stage renal disease program: trends over the past 18 years. Am J Kidney Dis. 1992;20:3-7.

20. Rodríguez JA, López J, Clèries M, Vela E. Vascular access for haemodialysis-an epidemiological study of the Catalan renal registry. Nephrol Dial Transplant. 1999;14:1651-7

21. Schmidli J, Widmer MK, Basile C, de Donato G, Gallieni M, Gibbons CP, et al. Editor's choice - vascular access: 2018 clinical practice guidelines of the European Society for Vascular Surgery (ESVS). Eur J Vasc Endovasc Surg. 2018;55:757-818.

22. Vascular Access Work Group. Clinical practice guidelines for vascular access. Am J Kidney Dis. 2006;48(Suppl 1):S248-73.

23. Kim YO, Choi YJ, Kim Jl, et al. The impact of intima-media thickness of radial artery on early failure of radiocephalic arteriovenous fistula in hemodialysis patients. J Korean Med Sci. 2006;21:284-9.

24. Charytan D, Mauri L, Agarwal A, Servoss S, Scirica B, Kuntz RE. The use of invasive cardiac procedures after acute myocardial infarction in long-term dialysis patients. Am Heart J. 2006:152:558-64

25. Silva MB Jr, Hobson RW 2nd, Pappas PJ, Jamil Z, Araki CT, Goldberg MC, et al. A strategy for increasing use of autogenous hemodialysis access procedures: impact of preoperative noninvasive evaluation. J Vasc Surg. 1998;27:302-7 discussion 307-8

26. Allon M, Lockhart ME, Lilly RZ, Gallichio MH, Young CJ, Barker J, et al. Effect of preoperative sonographic mapping on vascular access outcomes in hemodialysis patients. Kidney Int. 2001;60:2013-20.

27. Ilhan G, Esi E, Bozok S, Yürekli I, Özpak B, Özelçi A, et al. The clinical utility of vascular mapping with Doppler ultrasound prior to arteriovenous fistula construction for hemodialysis access. J Vasc Access. 2013;14:83-8.

28. Wong CS, McNicholas N, Healy D, Clarke-Moloney M, Coffey JC, Grace PA, et al. A systematic review of preoperative duplex ultrasonography and arteriovenous fistula formation. J Vasc Surg. 2013;57:1129-33.

29. Georgiadis GS, Charalampidis DG, Argyriou C, Georgakarakos El, Lazarides MK. The necessity for routine pre-operative ultrasound mapping before Arteriovenous fistula creation: a meta-analysis. Eur J Vasc Endovasc Surg. 2015:49:600-5

30. Kosa SD, Al-Jaishi AA, Moist L, Lok CE. Preoperative vascular access evaluation for haemodialysis patients. Cochrane Database Syst Rev. 2015: 2015(9):CD007013. https://pubmed.ncbi.nlm.nih.gov/26418347/.

31. Zonnebeld N, Maas T, Huberts W, van Loon MM, Delhaas T, Tordoir J. Preoperative duplex ultrasonography in Arteriovenous fistula creation: intraand inter-observer agreement. Eur J Vasc Endovasc Surg. 2017;54:613-9.

\section{Publisher's Note}

Springer Nature remains neutral with regard to jurisdictional claims in published maps and institutional affiliations. 